\title{
A MEDIAÇÃO SANITÁRIA COMO ALTERNATIVA À JUDICIALIZAÇÃO DO DIREITO À SAÚDE
}

\author{
Amanda Inês Morais Sampaio* \\ Rebecca Falcão Viana Alves**
}

\section{RESUMO}

O presente trabalho objetiva discutir se a mediação sanitária é, de fato, uma alternativa satisfatória para a judicialização, que ainda é um meio de garantir efetividade do direito à saúde aos enfermos. Para melhor compreensão do tema, dividiu-se o estudo em três partes: uma breve explicação sobre a judicialização; a conceituação de mediação sanitária e uma análise entre a mediação sanitária e a judicialização. A metodologia utilizada foi a de pesquisa bibliográfica realizada através de fontes primeiras como livros, artigos de revistas e a legislação vigente, sendo usado conjuntamente o método dedutivo como uma abordagem geral sobre o tema pesquisado.

Palavras-Chaves: Mediação; Judicialização; Acesso a Justiça; Direito à Saúde; Meios Pacíficos de Solução de Conflito.

\section{THE HEALTH CARE MEDIATION AS AN ALTERNATIVE TO THE JUDICIALIZATION OF THE RIGHT TO HEALTH}

\begin{abstract}
The present research has the purpose to discuss if health care mediation is a satisfactory alternative for the judicialization, that is to prevent the effectiveness of the right to health to diseased. The evaluation of the article is the evaluation in the section of three parties: a brief explanation on the judicialization; a conception of sanitary mediation and an analysis between a sanitary mediation and a judicialization. The methodology used was bibliographical research conducted through sources such as books, journal articles, and a literature review was used together with the deductive method as a general approach on the researched topic.
\end{abstract}

\footnotetext{
*Mestranda em Direito pela Universidade Federal de Sergipe (UFS), bolsista CAPES. Membro do Grupo de Pesquisa Eficácia dos Direitos Humanos e Fundamentais: seus reflexos nas relações sociais (GEDH/UFS/CNPq), do Grupo de Estudos e Pesquisa Educação e Contemporaneidade (EDUCON/UFS/CNPq) e do Grupo de Pesquisa Direito Público, Educação Jurídica e Direitos Humanos na Contemporaneidade (PEJDH/UNIT/CNPq). Especialização em andamento em Direito Processual Civil pela Escola Judicial do Estado de Sergipe (EJUSE). Email: amandaimsamapaio@gmail.com

** Mestranda em Direito pela Universidade Federal de Sergipe (UFS), bolsista CAPES. Membro do Grupo de Pesquisa Eficácia dos Direitos Humanos e Fundamentais: seus reflexos nas relações sociais (GEDH/UFS/CNPq), Especialista em Direito do Trabalho e Previdenciário pelo Centro Universitário da Faculdade Guanambi UNIFG. Email: Rebecca.f.v.alves@gmail.com

Rev. de Formas Consensuais de Solução De Conflitos | e-ISSN: 2525-9679 | Goiânia| v. 5 | n. 1 | p. 1-20| Jan/Jun. 
Key-Words: Mediation; Judicialization; Access Justice; Right to Health; Alternative Dispute Resolution.

\section{INTRODUÇÃO}

Provavelmente, um dos maiores problemas enfrentado por qualquer sistema jurídico no mundo seja o de conseguir efetivar suas normas - leis e princípios. Em outras palavras, tanto concretizar os direitos que o ordenamento jurídico propõe como fazer seus cidadãos obedecê-los. Naturalmente, ou até esperadamente, o Brasil não seria uma exceção à problemática de como concretizar os direitos que o País garante e estabelece legalmente.

A Constituição Federal de 1988, conhecida como Constituição Cidadã por trazer valores e visões dos mais distintos setores da sociedade que se reuniram na Assembléia Nacional Constituinte para criá-la, é o documento jurídico-político que organiza a República Federativa do Brasil como Estado Soberano, porém mais do que apenas organizar o Estado e seus Poderes, a Constituição de 1988 também tratou de reconhecer e de estabelecer os mais diversos direitos individuais, sociais, coletivos e difusos. Por tal motivo, na época de sua promulgação - e há quem diga que até hoje - ela foi, e ainda o é, considerada uma das mais avançadas e democráticas Cartas Republicanas do mundo.

Dentre a variada gama de direitos fundamentais que a Constituição Federal delega ao Estado como dever de fornecer aos seus cidadãos se escolheu o direito à saúde para ser tratado - ainda que de modo indireto - no presente artigo. $\mathrm{O}$ direito à saúde tem a primeira menção feita no artigo $6^{\circ}$ da Carta Magna, o qual estabelece que a saúde é um direito social, porém ele retorna a ser comentado e regulado nos artigos de 196 a 200 da Constituição.

A Constituição declara que o direito à saúde é direito de todos e dever do Estado, sendo que ele deve ser garantido mediante a realização de políticas públicas, ela também cria o Sistema Único de Saúde e permite que haja a assistência da iniciativa privada. Este ponto é interessante, por notar que não há um empecilho para que haja prestação privada de saúde no sistema brasileiro, o que abre margem para uma concorrência entre o sistema público e o privado. Em geral, haver a concorrência de serviços é vantajosa para seus consumidores, pois os serviços precisam arrumar meios de serem mais eficazes para atrair sua clientela. Algo que

Rev. de Formas Consensuais de Solução De Conflitos | e-ISSN: 2525-9679 | Goiânia| v. 5 | n. 1 | p. 1-20| Jan/Jun. 2019 
infelizmente não ocorre no Brasil, sendo ambos os sistemas de serviços de saúde insuficientes e negligentes, quando não sucateados.

Por conta dessa carência ou ausência de prestação de serviços adequados pelo sistema público e/ou impossibilidade de arcar com os gastos do serviço privado, criou-se uma solução um tanto quanto prejudicial e ao mesmo tempo necessária diante da situação de desespero que os cidadãos se encontravam: a de pleitear na Justiça a efetivação do seu caso particular que deriva do direito à saúde. Ações sobre autorização para cirurgias, criação de leitos, entrega de remédios, casos que variavam do problema mais simples, por assim dizer, até questões milionárias de tratamentos de alto risco. Todas essas ações chegam diariamente ao Judiciário, tanto que a doutrina nomeou de judicialização essa necessidade de pleitear na Justiça a concretização de direitos que devem ser fornecidos pelo Poder Público.

Ao observar os constantes debates sobre a judicialização da saúde e seus benefícios e prejuízo, além de observar o advento do Código de Processo Civil de 2015 e da Lei n ${ }^{\circ}$ 13.140/2015, que trouxeram a ideia dos meios de resolução de conflito extrajudiciais, gerouse a ponderação que ora é objetivo do presente artigo: a de compreender se a mediação é uma alternativa viável para que se evite a judicialização da saúde sem que isso prejudique o acesso do cidadão à Justiça. Porque não se pode negar que há a necessidade de pleitear aquilo que não é oferecido ou é negado ao cidadão, porém haveria alguma forma melhor de resolver esse impasse entre o cidadão e o Poder Público?

Para tentar responder tal indagação, o presente trabalho se guiará pelas seguintes perguntas: O que é a judicialização do direito à saúde? Quais os prejuízos que a judicialização da saúde traz? O que é mediação sanitária? e Quais os benefícios que a mediação sanitária pode trazer para o usuário do sistema de saúde e para o poder público? Assim, espera-se que ao responder tais perguntas em seus devidos tópicos, seja possível compreender ao final se de fato a mediação sanitária é uma alternativa mais benéfica que a judicialização da saúde.

A metodologia utilizada na presente pesquisa teve o fim exploratório para compreender o que é a mediação sanitária e como ela pode ser utilizada para que seja evitada a judicialização da saúde. Quanto à abordagem foi dedutiva, ao utilizar um panorama geral para entender o tema abordado. O método de abordagem quanto aos objetivos será qualitativo, pois se busca um conhecimento valorativo que não será expresso em números e nem de forma exata. Por fim, houve o levantamento bibliográfico acerca dos conceitos de judicialização do direito à saúde e de mediação sanitária; logo após foi feita a pesquisa documental, sendo Rev. de Formas Consensuais de Solução De Conflitos | e-ISSN: 2525-9679 | Goiânia| v. 5 | n. 1 | p. 1-20| Jan/Jun. 2019 
utilizadas fontes primárias como normas jurídicas brasileiras, especialmente, a Constituição Federal, a Lei $\mathrm{n}^{\circ}$ 13.140/15 e o Código de Processo Civil, bem como livros e artigos de revistas voltados para o assunto de direito à saúde, judicialização e mediação sanitária.

\title{
1. BREVE EXPLICAÇÃO SOBRE A JUDICIALIZAÇÃO DO DIREITO À SAÚDE
}

Antes de se estabelecer o que é a judicialização do direito à saúde, é necessário compreender o que é esse termo judicialização? A melhor explicação para esse termo é o conceito que Barroso (2009, p. 19) traz:

\begin{abstract}
Judicialização significa que algumas questões de larga repercussão política ou social estão sendo decididas por órgãos do Poder Judiciário, e não pelas instâncias políticas tradicionais: o Congresso Nacional e o Poder Executivo - em cujo âmbito se encontram o Presidente da República, seus ministérios e a administração pública em geral. Como intuitivo, a judicialização envolve uma transferência de poder para juízes e tribunais, com alterações significativas na linguagem, na argumentação e no modo de participação da sociedade.
\end{abstract}

Compreende-se das palavras de Barroso que a judicialização é mais do que a tradicional ideia de um aumento excessivo de demandas - normalmente relativas às políticas públicas no Judiciário. Pode-se depreender de sua a ideia que a judicialização necessariamente ocorre com a transferência do poder de decisão, e por consequência dela própria, para o Judiciário, sendo esta não apenas uma visão de Barroso. Observa-se que igualmente é o pensamento de Machado (2008, p. 82) “A judicialização, neste sentido, depende acima de tudo da opção dos juízes de participarem do processo de decisão política, no lugar de simplesmente deixarem que as decisões sejam tomadas nos órgãos e instituições usualmente competentes para tanto." Em todo seu texto, Machado (2008) deixa transparecer esse pensamento de que a judicialização é uma forma de expansão do poder do Judiciário ao tomar para si a decisão de questões e conflitos que originalmente não lhe pertencem.

Ao observar os pensamentos de ambos os autores, nota-se que a judicialização, de fato, não é a simples demanda - ou até mesmo, excesso de demandas - para o Judiciário de políticas públicas ou de direitos individuais, coletivos ou sociais. No entanto, apesar de compreender o pensamento de Barroso e de Machado, a verdade é que a prática reiterada de pleitos e de decisões acerca do que foi chamado de "questões da seara tradicionalmente 
políticas”, ou seja, questões da seara da Administração Pública, o poder de decisão acaba por se transferir - ainda sem que seja a intenção - para o Poder Judiciário.

Deve-se igualmente relevar o fato de que enquanto há o posicionamento de que a judicialização é algum ruim; há o posicionamento de que ela é necessária, uma vez que há falha ou deficiência na prestação do serviço e na capacidade da Administração Pública de resolver o conflito com o cidadão que necessita de sua prestação, é o que se conclui da leitura de Ventura et al (2010). Inclusive, o texto é aberto com o seguinte pensamento sobre o assunto tratado “(...) o fenômeno da judicialização da saúde expressa reivindicações e modos de atuação legítimos de cidadãos e instituições, para a garantia e promoção dos direitos de cidadania amplamente afirmados nas leis internacionais e nacionais." (VENTURA ET AL, 2010, p. 78). Os autores afirmam que no contexto democrático a judicialização da saúde é uma forma legítima que os cidadãos têm para buscarem a concretização do direito à saúde.

Ressalta-se que mesmo autores que defendem que a judicialização é prejudicial para o Estado e para a sociedade de modo geral não desqualificam que ela é um modo legítimo - e até pouco tempo também era o único - que o cidadão tinha para resolver os conflitos entre ele e a Administração Pública. Em verdade, é quase unânime a ideia de que a judicialização e o excesso de demandas para efetivação de direitos sociais fundamentais é reflexo direto da ineficiência e má gestão da Administração Pública. Exemplo de autores que expressa tal ideia é Cruz e Nez (2017, p. 4) ao afirmarem que "No que se refere à saúde pública, a falta de resolutividade do Executivo em relação aos cuidados garantidos pela $\mathrm{CF} / 88$ à população é fator multiplicador de demandas judiciais." Em outras palavras, justamente por não ter a sua disposição o serviço de saúde garantido na Constituição e também por não obterem resposta da Administração Pública ao seu clamor, é que o cidadão se vê quase que obrigado a recorrer ao Judiciário para ter seu direito não só garantido como concretizado.

Outra autora que adere essa posição é Oliveira (2013), a qual defende, em seu texto, que a ineficiência do Poder Executivo em cumprir com seus deveres constitucionais e sua inércia e inabilidade em resolver os conflitos que surgem dessa falta de prestação efetiva dos serviços geram as demandas judiciais, pois esse seria o único meio restante que o cidadão teria para tentar garantir a realização de seu direito. Para Oliveira (2013) há uma lacuna entre o que o Poder Executivo deve oferecer aos cidadãos, conforme a Constituição determina, e o que realmente a sociedade recebe de prestação de serviço, sendo esse o motivo pelo qual o

Rev. de Formas Consensuais de Solução De Conflitos | e-ISSN: 2525-9679 | Goiânia| v. 5 | n. 1 | p. 1-20| Jan/Jun. 2019 
indivíduo necessita recorrer à demanda judicial para ter seus direitos efetivados. Segundo as palavras da autora:

O ingresso de ações judiciais é uma forma que os cidadãos encontram para garantir seus direitos, sendo, portanto, legítima uma ação judicial que vise obrigar o poder público a fornecer um medicamento contemplado em suas políticas públicas previamente elaboradas e não disponível no Sistema Único de Saúde - SUS, posto que vise a garantir um direito fundamental. (OLIVEIRA, 2013, p.81)

Ao ponderar sobre os pontos de vistas citados anteriormente, o presente trabalho compreende que jucidialização é a demanda em excesso que acaba por transferir o poder de decisão do ente público, que originalmente o tinha, para o Poder Judiciário. Nesse caso, a judicialização da saúde são as excessivas demandas sobre problemas relacionados à concretização e a eficácia da prestação do serviço ou insumos da saúde de modo que estão passando o poder de decisão sobre tais conflitos e problemas da Administração Pública do ente político, que deveria prestar o serviço ou oferecer o bem para o cidadão, para a Justiça.

Após este primeiro momento de compreensão sobre o que é a judicialização da saúde, passa-se para a resposta da segunda pergunta guia do estudo, a qual trata sobre os prejuízos que a judicialização da saúde traz. Afinal, se a via judicial é uma forma viável dentro do nosso sistema jurídico para garantia de direitos individuais e sociais, porque a judicialização seria prejudicial? Em verdade, a judicialização em si não é necessariamente prejudicial, ela é parte, por assim dizer, da narrativa da vida em sociedade. O que a torna prejudicial é a multiplicidade de suas demandas, ou seja, seu excesso. Quando as demandas do direito à saúde deixam de ser a exceção e passam a ser a regra, elas acabam por interferir no frágil universo do Sistema Único de Saúde - seja orçamentário, planejamento, etc.

Para observar quais são os principais prejuízos que a judicialização acarreta observase o estudo realizado por Cruz e Nez (2017), que corroboram com a ideia de que o excessivo protagonismo do Judiciário, especificamente no âmbito da saúde, tende a criar mais prejuízos que evitá-los. Cruz e Nez (2017) elencam quatro principais prejuízos causados pela judicialização excessiva do direito à saúde, sendo eles: a quebra da equidade; a criação de desorganização no sistema; o superdimensionamento do preço e a exposição do Estado ao ponto que ele próprio configurará como autor e réu na ação. Num breve relato, seguem as explicações de Cruz e Nez (2017) sobre cada um dos pontos levantados.

A quebra da equidade que Cruz e Nez (2017) trazem é pelo fato de que a judicialização privilegia a parte autora da demanda judicial em detrimento dos demais Rev. de Formas Consensuais de Solução De Conflitos | e-ISSN: 2525-9679 | Goiânia| v. 5 | n. 1 | p. 1-20| Jan/Jun. 2019 
usuários do sistema público de saúde, uma vez que conforme eles explicam “(...) o cumprimento do comando judicial terá preferência, dando espaço a furos de filas de cirurgias, consultas e exames, quebra de estoque de medicamentos, etc.” (CRUZ; NEZ, 2017, p. 5). De fato, com a regularidade das decisões ordenando que sejam cumpridas sob pena de multa ou de sequestro, o próprio Poder Judiciário está priorizando aqueles que puderam adentrar com uma demanda judicial ao invés da sociedade em geral, bem como aqueles que estavam na mesma situação, mas que não puderam ou são ignorantes sobre a possibilidade de pleitear suas necessidades em juízo.

A criação de desorganização no sistema é tratada como o reflexo direto da ingerência nas políticas de alocação de recursos financeiros, humanos ou estruturais que as decisões judiciais criam, conforme Cruz e Nez (2017). Os autores ainda observam que a individualização das demandas acaba por criar um prejuízo ao coletivo, pois interferem no orçamento público, além de desestruturarem o planejamento das políticas públicas. Para eles, a judicialização não pode servir como um mecanismo para ultrapassar os limites éticos e técnicos do Sistema Único de Saúde, porém é o que ela efetivamente faz. O superdimensionamento do preço, para Cruz e Nez (2017), nada mais é que uma forma de superfaturar o preço do produto ou serviço, visto que ao exigir que seja realizado com urgência e de modo imediato, a Administração Pública adquire bens com um preço bastante elevado do que ela normalmente iria adquirir - através de licitações e lotes.

O último prejuízo é a exposição do Estado, os autores afirmam que nesse caso devido a judicialização ocorre a situação anômala, na qual, provavelmente, a própria unidade federativa integrará como atores em todos os quadros do litígio. Explicam Cruz e Nez (2017) que a maioria das ações são feitas pela Defensoria Pública do Estado, tendo como réus o estado-membro e o município, sendo assim as Procuradorias do Estado e do Município elaboraram a defesa, além disso, haverá a participação do Ministério Público como fiscal da lei para, por fim, ter um magistrado que decidirá sobre a questão, todos os órgãos elencados com exceção da procuradoria do município - vinculados ao mesmo ente político. Em outras palavras, há o movimento de distintas instituições de um mesmo ente público com a finalidade de alcançar a tutela jurídica frente ao próprio ente público. Por tal razão, compreendem os autores que o estado-membro se expõe e retrata a própria ineficiência. Apesar de concordar com os autores, crê-se que o fato mais notável desse envolvimento de

Rev. de Formas Consensuais de Solução De Conflitos | e-ISSN: 2525-9679 | Goiânia| v. 5 | n. 1 | p. 1-20| Jan/Jun. 2019 
diversos órgãos e entes da unidade federal é o custo que ele tem, justamente por envolver tantas instituições num mesmo processo.

Nota-se que os autores foram taxativos em dizer que não houve o esgotamento das críticas, eles apenas trabalharam mais profundamente nesses quatro prejuízos por eles elencados. E apesar de não falar diretamente, acabaram por citar também aquela que é a crítica que normalmente vem à mente assim que tratamos do assunto, o fato de que uma ação judicial é onerosa para os cofres públicos - sem necessariamente ser a onerosidade dos serviços e insumos adquiridos em caráter emergencial e nem a desorganização orçamentária. Como se observa na fala de Delduque e Castro (2015) eles afirmam que apesar de não haver uma pesquisa específica de quanto uma ação unitária em matéria de saúde custa aos cofres públicos, eles usaram um comparativo que foi o estudo do Instituto de Pesquisa Econômica Aplicada (Ipea) sobre o custo de um processo judicial de execução fiscal, que custa cerca de $\mathrm{R} \$ 7.063,74$ (sete mil, sessenta e três reais e setenta e quatro centavos). Deduzindo-se que os gastos são aproximados pode-se notar que o excessivo volume das demandas sobre saúde onera bastante os cofres públicos, tanto pelos preços dos próprios processos como pela desorganização no orçamento público da saúde.

\section{BREVES CONSIDERAÇÕES SOBRE A MEDIAÇÃO SANITÁRIA}

Nas últimas duas décadas, o estudo e a utilização dos métodos consensuais de solução de conflitos vêm ganhando força e cada vez mais espaço no universo jurídico do Brasil. Formas consensuais que fizeram parte do ordenamento brasileiro desde o período colonial, como a arbitragem e a conciliação, estão novamente em voga como meios de resolução de conflitos mais atraente que o Judiciário. Outra forma de resolução pacífica de conflitos que está sendo estimulada sua utilização e sua pesquisa - apesar de não ter uma tradição histórica no ordenamento pátrio como os métodos anteriormente citados - é a mediação, a qual recentemente ganhou prestígio legal ao ser prevista no Código de Processo Civil de 2015, além de receber lei própria que a regulamentasse: a Lei n ${ }^{\circ}$ 13.140/15.

A mediação, segundo Bacellar (2016) é o processo no qual um terceiro imparcial auxiliará as partes em conflito a chegarem a uma solução construída por ambos. Deste modo,

Rev. de Formas Consensuais de Solução De Conflitos | e-ISSN: 2525-9679 | Goiânia| v. 5 | n. 1 | p. 1-20| Jan/Jun. 2019 
pode-se concluir que é uma forma democrática de resolução de conflitos, uma vez que a tomada de decisão pertence aos litigantes. Observa-se que tal conceito é o utilizado pela Lei $\mathrm{n}^{\circ} 13.140$ (BRASIL, 2015) no parágrafo único do seu primeiro artigo ${ }^{1}$.

Nota-se que a legislação acertadamente internalizou o conceito que a doutrina majoritária já utilizava, consolidando o que é mediação para o ordenamento jurídico pátrio. Atenta-se ainda que no final do caput do artigo primeiro da lei estabelece que a mediação é uma forma viável de resolução de conflitos no âmbito da Administração Pública. Tal permissão legal é importante para o tema abordado no presente trabalho que envolve diretamente o Sistema Único de Saúde (SUS) e os gestores públicos.

Apesar de que a probabilidade de haver um impedimento para o uso da mediação por parte da Administração Pública fosse relativamente pequena, pois pelo que se depreende das leituras de Assis (2013) e de Ribeiro (2018) o próprio Poder Público já estava buscando meios extrajudiciais para a resolução dos conflitos relativos ao direito à saúde. Em seu artigo Assis (2013) trata da ação institucional de mediação sanitária realizada pelo Ministério Público de Minas Gerais, que foi instituído em 2012. Já Ribeiro (2018) além da ação institucional do Ministério Público de Minas Gerais traz outros exemplos, um deles sendo a Câmara Permanente Distrital de Mediação em Saúde, realizada em parceria pela Secretaria do Estado de Saúde e a Defensoria Pública do Distrito Federal, também anterior a Lei ${ }^{\circ}$ 13.140/15. Deixando claro que a própria Administração Pública tem estimulado e utilizado da mediação, em especial, nos casos que envolvem questões sobre a saúde.

Devido a sua natureza de envolver as partes conflitantes para que ambos busquem a solução para a controvérsia - além de estimular que haja o diálogo e a compreensão da narrativa de todos os envolvidos no conflito - é lógico que a mediação seria a forma de solução pacífica escolhida pelo Poder Público para tentar maximizar o possível encontro de uma solução que efetivamente satisfaça aos envolvidos no conflito. Tal intenção pode ser observada nas palavras de Assis (2015, p. 4) quando ele explica o que é mediação sanitária e afirma que ela "Parte do pressuposto de que a atuação solitária de quaisquer desses atores, que integram esse fundamental Sistema de Saúde, não contribui para a necessária efetivação do

\footnotetext{
${ }^{1}$ Art. $1^{\circ}$ Esta Lei dispõe sobre a mediação como meio de solução de controvérsias entre particulares e sobre a autocomposição de conflitos no âmbito da administração pública.

Parágrafo único. Considera-se mediação a atividade técnica exercida por terceiro imparcial sem poder decisório, que, escolhido ou aceito pelas partes, as auxilia e estimula a identificar ou desenvolver soluções consensuais para a controvérsia.

Rev. de Formas Consensuais de Solução De Conflitos | e-ISSN: 2525-9679 | Goiânia| v. 5 | n. 1 | p. 1-20| Jan/Jun. 2019
} 
Direito à Saúde.” Nessa passagem, Assis declara que o trabalho da mediação é o de garantir a participação de todos os atores como ele chama as partes que formam o Sistema de Saúde, não apenas o setor público, como a própria sociedade e os próprios órgãos do Judiciário e auxiliares da Justiça. Compreende-se das palavras do autor que a ação solitária de um desses atores que integram o Sistema de Saúde não gera nenhum tipo de concretização do direito à saúde. De modo que se pode ainda concluir, pelo que foi visto sobre a judicialização, que a ação solitária que Assis se refere, pode gerar, em verdade, prejuízo para o Sistema Público de Saúde.

Compreendido o que é mediação e observado a principal característica que a levou a ser escolhida pelo Poder Público como a forma consensual de resolução de controvérsias, resta agora ver o que é a mediação sanitária. Apesar de ser quase óbvia a dedução de que mediação sanitária é a mediação aplicada no âmbito do direito sanitário, ou seja, conflitos relativos ao direito à saúde, ela é um pouco mais do que o óbvio. Utiliza-se da explicação de Delduque sobre mediação sanitária:

A Mediação Sanitária é um modelo alternativo de resolução de conflitos na área da saúde. As relações em saúde transcendem a ótica bilateral do médico com o paciente, para envolver muitos outros atores presentes em um sistema de saúde, daí advindo conflitos de toda a ordem, internos e externos ao sistema, criando condições para a judicialização. (DELDUQUE, 2015, P. 6).

Para a autora, é evidente a relação direta entre a mediação sanitária e a judicialização. O que é natural, haja vista que seu artigo trata sobre como a mediação sanitária é efetivamente uma alternativa para se combater a judicialização. É interessante observar, ainda, que na explicação de Delduque (2015), ela separa os conflitos internos como aquele de organização, conflitos entre profissionais e assistenciais e como conflitos externos aqueles que são gerados foras do sistema, mas que refletem dentro dele, de acordo com ela, os conflitos sociais e os legais. De qualquer sorte, tanto em conflitos internos quanto nos externos há a tendência a gerar a judicialização da controvérsia, conforme Delduque, o que para ela é o problema a ser combatido.

Apesar do enfoque de método de resolução de conflitos, é interessante observar que a mediação sanitária, para além de resolver as controvérsias, tem um viés de compreender os atritos que geram os problemas da saúde pública brasileira. Tal lado pode ser visto nas palavras de Assis $(2015$, p. 4) quando ele afirma que a ação institucional de mediação sanitária do Ministério Público de Minas Gerais visa discutir os desafios coletivos da saúde, Rev. de Formas Consensuais de Solução De Conflitos | e-ISSN: 2525-9679 | Goiânia| v. 5 | n. 1 | p. 1-20| Jan/Jun. 
em âmbito micro ou macrorregional, realizado de modo que envolva a todos os atores do Sistema, sendo jurídicos ou não, para construir um espaço democrático, compartilhado que respeita os distintos saberes, “(...) de forma a reduzir a tensão e o confronto entre eles (...)". Para o autor, é através desse espaço democrático e respeitoso que a mediação proporciona entre médicos, promotores, cidadãos, gestores e todos os atores do Sistema de Saúde, que se resulta a efetiva construção de políticas públicas de saúde universais, integrais e igualitárias. Compreensivelmente, isso ocorre porque apenas com a participação de todos aqueles que integram e formam o Sistema de Saúde é que se pode ter real noção das deficiências e necessidades que o sistema possui. Além disso, é através da combinação dos diversos conhecimentos que podem nascer soluções inovadoras que jamais poderiam ter sido pensadas sem a participação do detentor do outro saber.

Apesar de parecer uma solução um tanto quanto utópica, a mediação sanitária tem sido usada em diversas localidades do Brasil e em algumas delas já se é possível ver seus resultados. Especificamente, no caso da ação institucional de mediação sanitária do Ministério Público de Minas Gerais, uma vez que o Promotor Assis, além de tratar de perto sobre o assunto publicou dois artigos com um espaço de dois anos entre eles. No primeiro artigo Assis (2013) não podia apresentar dados efetivos, pois a ação institucional estava, basicamente, sendo realizada naquele momento.

O segundo artigo já trouxe algumas informações de como funciona seu projeto e alguns resultados da ação institucional de mediação sanitária. Conforme Assis (2015) o projeto funciona com a realização de encontros que ocorrem em todo o território estadual. O autor tentar trazer um fluxograma demonstrando como essas reuniões acontecem: primeiro há o acionamento do Ministério Público através do Centro de Apoio Operacional das Promotorias de Justiça de Defesa da Saúde (CAOSAUDE), então há uma avaliação da demanda - que se possível será feita junto à Secretaria do Estado de Saúde; há a coleta dos principais indicadores microrregionais coletivos de saúde para então ser feita a elaboração da programação e expedição de convites para todos os interessantes que desejem participar, há a reunião de mediação, onde ocorre a discussão dos problemas coletivos de saúde que foram analisados nas etapas anteriores, após a deliberação e a construção de um consenso há a criação da Comissão de Trabalho Microrregional, que observará cada município que integra a microrregional para realizar um diagnóstico sobre as questões debatidas; por fím há a elaboração de uma ata da reunião. Ficando o CAOSAUDE e a SES-MG responsáveis pelo Rev. de Formas Consensuais de Solução De Conflitos | e-ISSN: 2525-9679 | Goiânia| v. 5 | n. 1 | p. 1-20| Jan/Jun. 2019 
acompanhamento dos resultados da mediação. O autor afirma que já houve mais de 70 reuniões em todo o estado, e que já houve bons resultados dessa ação institucional.

Em verdade, Assis (2015) lista os principais resultados numa enumeração de a até u, sendo que os principais podem ser considerados os seguintes: o estabelecimento de convênios de cooperação técnica entre Entes públicos; corresponsabilidades financeiras; melhoria das condições de trabalho nas unidades de saúde; intervenção administrativa ou judicial nas administrações hospitalares com grave comprometimento assistencial, gestão desqualificada e desequilíbrio econômico-financeiro; aumento de número de leitos especializados (UTI) na região da saúde; atualização dos estatutos e regimentos dos prestadores hospitalares conveniados ao SUS; cursos de especialização de direito sanitário pela Escola de Saúde Pública de Minas Gerais e o último que o autor elenca é a redução dos confrontos, conflitos e de demandas judiciais reflexivas.

É interessante observar que o autor deixou propositalmente a redução de conflitos e demandas judiciais por fim, após uma longa lista de outras benesses que ocorreram após a criação da mediação sanitária utilizada pelo CAOSAUDE. Compreende-se que ter deixado a redução da demanda judicial por último foi feito intencionalmente por Assis, uma vez que quase sempre que se discute sobre mediação em conflitos de saúde, ou seja, mediação sanitária, a primeira coisa que se debate é - e que oportunamente é o assunto do presente trabalho - que a mediação é uma forma de reduzir as excessivas demandas judiciais, é um meio de "desafogar o judiciário", o que pode ser considerado apenas um dos benefícios da mediação. Por isso, ao listar todos os principais resultados da mediação sanitária em Minas Gerais e deixar a diminuição das demandas judiciais por último, Assis parece ter invertido essa ideia de que a mediação serve apenas para ser uma válvula de escape do judiciário, demonstrando que a mediação sanitária pode trazer vários e diversos benefícios que não sejam apenas a redução de demandas judiciais e, por consequência, dos gastos com as ações movidas no judiciário.

Apesar de não serem tão detalhadas como a experiência do CAOSAUDE, há ainda a Câmara Permanente Distrital de Mediação em Saúde - CAMIDES em Brasília e o Comitê Interinstitucional de Resolução Administrativa de Demandas da Saúde - CIRADS no Rio Grande do Norte. Ambos são mencionados por Ribeiro (2018) e Cruz e Nez (2017), no

Rev. de Formas Consensuais de Solução De Conflitos | e-ISSN: 2525-9679 | Goiânia| v. 5 | n. 1 | p. 1-20| Jan/Jun. 2019 
entanto nenhum dos autores se aprofunda na questão, trazendo a CAMIDES e o CIRADS apenas como exemplos da instituição da mediação sanitária como resolução de conflitos. Consoante Cruz e Nez (2017, p. 13) "Com a CAMEDIS, a Defensoria, ao invés de, via de regra, ingressar judicialmente com as demandas de saúde, passou também a buscar soluções extrajudiciais para os conflitos, por meio da prática da mediação.” Em outras palavras, há uma opção para que não haja necessidade de se judicializar o conflito, em verdade, os próprios autores afirmam ainda que a CAMIDES traz a possibilidade de retirar o pleito que já está em juízo para ser resolvido extrajudicialmente. Já sobre o CIRADS, Ribeiro (2018) declara que ele é realizado através de uma ação conjunta entre a Procuradoria da União no Rio Grande do Norte, a Defensoria Pública da União, procuradores estaduais e municipais, bem como secretarias estaduais e municipais da saúde. "O Cirads busca a solução administrativa dos conflitos na área de saúde, por meio da análise de casos concretos em que o cidadão não conseguiu resolver sua pendência diretamente com o SUS.” (RIBEIRO, 2018, p. 72). Observa-se que tanto o CIRADS quanto a CAMIDES tendem a focar mais no efeito imediato de retirar o pleito do Judiciário e/ou já resolver a questão antes mesmo de ser levada para a Justiça.

Por fim, resta ponderar acerca de um ponto importante que sempre aparece nos debates sobre mediação, o qual naturalmente acaba envolvendo mediação sanitária da mesma forma: o Acesso à Justiça.

Conforme observa a explicação de Souza (2015) é necessário primeiro esclarecer a diferença entre acesso à Justiça formal e material. A autora explica que a visão que normalmente prevalece no entendimento sobre acesso à Justiça é a estrita visão formal, ou seja, a possibilidade de interpor ação no Judiciário. Como Souza afirma, essa é uma das feições mais importantes do acesso à Justiça, mas não é a única. Há ainda a visão material do acesso à Justiça, nesse caso, a autora explica que a visão material trata sobre a possibilidade de ter um processo e uma decisão justa, mas que não necessariamente venha do Poder Judiciário. Depreende-se de suas palavras que o acesso à Justiça é, na verdade, qualquer processo que possa de modo célere, sem impedir o devido contraditório, gerar uma solução satisfatória e definitiva. É com base no pensamento de acesso à Justiça material poder ser efetivado por processos que não sejam necessariamente judiciais que os métodos de resolução de conflitos ganharam espaço, inclusive legal, para atuarem em conjunto com o Judiciário na busca de decisões justas para os conflitos sociais.

Rev. de Formas Consensuais de Solução De Conflitos | e-ISSN: 2525-9679 | Goiânia| v. 5 | n. 1 | p. 1-20| Jan/Jun. 2019 
Com a possibilidade de diversos métodos de solução de conflito serem utilizados pelos cidadãos, nasce também a ideia do sistema de multiportas, ou seja, a existência de diversos meios pelos quais o cidadão pode buscar solucionar a sua controvérsia. É o que se depreende das palavras de Ribeiro (2018, p. 9) ao explica o que ele entende como o sistema de multiportas “(...) entende-se que várias são as formas de se solucionar determinada controvérsia e que tais métodos variados podem e devem interagir, proporcionando ao indivíduo um leque de opções para a busca da resolução do conflito, além da judicial.”. Ao ler tal excerto, pode-se notar que o sistema das múltiplas portas é a concretização do Acesso à Justiça material que Souza (2015) estabeleceu.

Ao observar tais ponderações, não restam dúvidas de que a mediação, bem como as outras formas de resolução de conflitos, é uma forma de garantir o Acesso à Justiça para os jurisdicionados, ampliando os métodos de como eles podem resolver seus conflitos.

\section{ANÁLISE ENTRE A MEDIAÇÃO SANITÁRIA E A JUDICIALIZAÇÃo}

Por fim, resta analisar os benefícios e os prejuízos da judicialização da saúde e da mediação sanitária. Para então concluir se é realmente vantajoso o uso da mediação como uma forma para a desjudicialização, que pode ser entendido tanto como o efeito de retiradas as demandas que existem no Poder Judiciário para serem resolvidas administrativamente, como também evitar que novas demandas sejam feitas ao resolver as questões diretamente com a Administração Pública.

Pelo que já foi observado da judicialização, compreende-se que seus benefícios são, em geral, individuais, uma vez que ela beneficia o cidadão ou o grupo de cidadãos que tenham entrado com a ação no judiciário. Em outras palavras, por muito tempo ela foi basicamente a única forma de acesso à Justiça que o cidadão possuía para buscar concretizar seu direito à saúde - lembrando que apesar de ser um direito social fundamental, ele também tem seu aspecto individual. Cita-se o seguinte excerto para observar essa dependência do cidadão com o Poder Judiciário para garantir a efetivação de seu direito:

(...) sem um canal administrativo capaz de ouvir e processar as diferentes demandas da sociedade nesta seara, sem informações disponíveis de forma clara a todos que necessitam de um medicamento ou tratamento de saúde. Este é um quadro que, freqüentemente, não confere ao cidadão outra alternativa senão buscar a tutela

Rev. de Formas Consensuais de Solução De Conflitos | e-ISSN: 2525-9679 | Goiânia| v. 5 | n. 1 | p. 1-20| Jan/Jun. 2019 
jurisdicional para ver garantido o seu direito. (grifo nosso)(MARQUES, 2008, p.67)

É clara a relação direta de falta de outro meio de resolução de conflito com a crescente judicialização na crítica de Marques (2008) sobre o despreparo do Poder Público para com as políticas públicas de saúde. Em verdade, esse próprio despreparo também é responsável pelo aumento da judicialização. Porém, o que se observa ser relevante é o fato de que já em 2008 a conclusão de que se precisaria de uma nova forma de solucionar as controvérsias administrativamente deveria ser uma opção, ou melhor, precisava ser uma opção para o cidadão ter seus direitos concretizados. Poucos anos depois, surgiriam as primeiras formas de mediação sanitária, como no caso do CAOSAUDE de Minas Gerais, provavelmente já derivadas desse debate de necessidade de outra alternativa que não só a tutela jurisdicional.

Por fim, outra vantagem que se atribui a judicialização - além de ter sido a única forma existente de concretização de um direito negado por um bom tempo - é a de contribuir para os avanços nas políticas públicas de saúde, uma vez que pela força imperativa das sentenças judiciais a Administração Pública - normalmente burocrática e morosa - tinha que descobrir uma forma ágil de realizar seus procedimentos e fornecimento de insumos. Todavia, ressalta-se que essa é uma vantagem considerada duvidosa, é verdade que não se pode discordar de que a Administração Pública é lenta e burocrática; porém também não se pode garantir que apenas o fato de ela ser forçada a agir com mais rapidez possa ser considerada uma vantagem completa. Isso porque esta vantagem se encontra no limite entre a desvantagem de desorganização do Sistema e da desvantagem de superdimensionamento dos preços.

As desvantagens já foram observadas no primeiro tópico deste artigo, porém apenas para fim de recordá-las, serão citadas: Onerosidade dos processos judiciais para os cofres públicos; a quebra da equidade; a criação de desorganização no sistema; o superdimensionamento do preço e a exposição da ineficiência do Estado. Pode-se dizer que a judicialização tem mais desvantagens que vantagens, porém ainda não há como negar que para o indivíduo que pleiteia uma ação judicialmente, a judicialização pode ser uma questão de vida ou morte.

Ao mesmo tempo, como se observa na leitura de Oliveira (2013) o excesso de judicialização gera um impacto imenso nos recursos públicos, o que cria uma desigualdade no acesso à saúde para todos e, por consequência impede que a saúde seja realizada de modo Rev. de Formas Consensuais de Solução De Conflitos | e-ISSN: 2525-9679 | Goiânia| v. 5 | n. 1 | p. 1-20| Jan/Jun. 2019 
universal. "Sem dúvida, percebe-se que a judicialização do acesso à saúde compromete a universalização da saúde, pois estabelece desigualdades entre os cidadãos e dificulta ainda a eficácia das políticas públicas de saúde.” (OLIVEIRA, 2013, p.81). Constata-se de suas palavras que a judicialização pode ser benéfica em âmbito individual do cidadão, mas que gera um prejuízo para toda a sociedade. Ademais, nota-se que a judicialização não está resolvendo, de fato, os problemas da falta ou da insuficiência dos serviços de saúde e fornecimento dos insumos, é o que se verifica do excerto de Cardoso (2017, p. 47) “(...) podese chegar à conclusão de se estar na vanguarda da proteção de direitos sociais e de proteção à cidadania. Entretanto, a realidade da saúde pública brasileira, mesmo com a ampla judicialização verificada, não parece ter melhorado.” Em outras palavras, a judicialização ampla e excessiva não tem realmente melhorado as condições dos serviços de saúde brasileiros, em verdade, ela é apenas a realização em caráter emergencial desses serviços. E como foi visto anteriormente, essa forma emergencial de proceder com o serviço está gerando mais desvantagens do que vantagens para a sociedade e para o Estado.

Parte-se para a análise das desvantagens e as vantagens da mediação. Iniciando-se pelas desvantagens que até então são consideradas poucas. Observa-se que para a mediação em geral Morais e Splenger (2008) elencam como desvantagens o fato de que se não for executada com cuidado a parte mais poderosa pode influenciar o resultado; a mediação também demanda tempo, apesar de ser mais rápida que o processo judicial, ela pode ser demorada pelo fato de que uma das partes pode impedir o progresso da mediação ou só pelo simples fato de levar em conta todos os atores do conflito - e no caso dos conflitos de saúde, são muitos atores para serem ouvidos; não é obrigatória a participação das partes e os mediadores não podem obrigá-los a participar do processo de mediação. Todavia, ressalta-se que essas são desvantagens gerais da mediação, não houve em nenhum dos materiais usados uma desvantagem apontada diretamente para a mediação sanitária. $\mathrm{O}$ que não quer dizer que ela não exista.

Morais e Splenger (2008) também elencam as vantagens da mediação: a privacidade ou confidencialidade; a construção de soluções com a participação de todos os envolvidos no conflito; a diminuição dos custos; a celeridade do processo de resolução do conflito; a diminuição do não cumprimento das decisões; redução do desgaste emocional das partes; e

Rev. de Formas Consensuais de Solução De Conflitos | e-ISSN: 2525-9679 | Goiânia| v. 5 | n. 1 | p. 1-20| Jan/Jun. 2019 
manutenção das relações anteriores ao conflito, dentre outros. Focando na mediação sanitária, as principais vantagens são a desjudicialização - tanto retirando as ações já existentes para serem resolvidas fora do âmbito judicial, como evitando que elas sejam judicializadas; a celeridade; a participação das partes conflitantes na construção da solução - ou seja, evitando assim a desorganização do sistema, uma vez que há a participação ativa da Administração Pública na solução que a vinculará ao seu cumprimento; diminuição dos custos tanto judiciais quanto os derivados do superdimensionamento dos preços de serviços e insumos. Concluemse essas vantagens ao analisar os principais resultados da mediação sanitária que Assis (2015) traz em seu texto sobre o CAOSAUDE. Além disso, o autor deixa claro durante todo o texto que a mediação sanitária é uma forma muito mais democrática e cidadã de resolver os conflitos, justamente porque envolve todos os interessados nas questões debatidas ou nos conflitos resolvidos, além de garantir uma melhor realização do serviço público de saúde para toda a sociedade e não apenas para uma pessoa ou um grupo de pessoas específico.

Por fim, ao observar as vantagens e desvantagens de ambos os institutos, é inevitável chegar à conclusão de que apesar de importante e de que durante muito tempo a judicialização foi a única forma de socorro do cidadão que se via despojado de seus direitos, ela está na realidade criando mais problemas para a própria concretização dos direitos sociais especificamente, o da saúde - que devem ser garantidos para toda a sociedade e não apenas no seu âmbito individual. Ao passo que, nos últimos anos, a ideia de mediar os conflitos diretamente com a Administração Pública, que é a responsável por realizar a prestação dos serviços públicos de saúde, vem ganhando força e, até então, vem se mostrando uma ótima opção para garantir não apenas o direito individual dos que procuram os entes públicos que oferecem esse serviço, como o da própria sociedade ao trazê-la para a discussão e a decisão sobre questões envolvendo as políticas públicas de seu interesse. Apesar de ainda ser cedo para garantir que esse método de resolução de conflitos é definitivamente a melhor solução para todos os problemas envolvendo a Administração Pública, ele tem se mostrado bem promissor.

\section{CONCLUSÃO}

Após uma breve consideração acerca da judicialização e dos seus efeitos para a Administração Pública - e até para a sociedade e para o Poder Judiciário - e acerca da

Rev. de Formas Consensuais de Solução De Conflitos | e-ISSN: 2525-9679 | Goiânia| v. 5 | n. 1 | p. 1-20| Jan/Jun. 2019 
mediação sanitária foi possível realizar uma análise sobre ambas, na qual se buscou observar pontos fortes e fracos que tanto a mediação quanto a judicialização têm. Com a finalidade de poder responder a pergunta que objetivou o presente estudo: a mediação é uma boa alternativa para se evitar a judicialização da saúde sem que isso prejudique o acesso do cidadão à justiça?

Em resumo, compreendeu-se que apesar de ser um meio legítimo de acesso formal à Justiça que o cidadão possui, a judicialização não está cumprindo seu papel de efetivamente proteger e promover os direitos dos cidadãos, uma vez que ao invadir a seara da Administração Pública e transferir a tomada de decisão do Poder Executivo para o Judiciário, a judicialização está criando mais efeitos negativos que positivos. Ela cria, dentre outros problemas, desigualdade entre a sociedade, privilegiando o atendimento daqueles que demandam judicialmente; e desequilibra os orçamentos da Administração Pública, além de ser onerosa para o próprio Judiciário.

Em contrapartida, observou-se que a mediação sanitária vem sendo uma promissora solução nos lugares em que ela foi implementada. Pelo fato de ser uma autocomposição, ou seja, um meio de resolução de conflito em que as partes conflitantes trabalham juntas para a construção da solução, a mediação tem sido considerada uma alternativa democrática e efetiva, visto que ao participarem ativamente da solução as partes tendem a não quebrar o acordo feito. Além disso, a mediação sanitária contempla a participação efetiva de todos os atores do sistema público de saúde: médico, gestores, enfermeiros, paciente, promotores, dentre outros. Com a participação desses atores, pode-se chegar a um acordo que não desorganize o orçamento ou os planos da Administração Pública, pois ela mesma participa da solução. Por fim, há que ressaltar a experiência de usar a mediação preventiva para que se evite chegar ao conflito, como foi visto no CAOSAUDE de Minas Gerais, que também tem resultados animadores.

Ponderando-se sobre as informações acima relatadas, conclui-se que a mediação sanitária está em plena sintonia com a teoria de multiportas do acesso à Justiça, ou seja, o cidadão, para ter verdadeiramente o acesso à Justiça material - e não apenas o formal precisa ter a sua disposição diversificadas formas de solucionar a controvérsia que lhe aflige. Para que ele possa decidir qual a forma de solução de conflito lhe parece mais adequada, além de que, caso a primeira forma venha a falhar, ele tenha a possibilidade de usar outro método

Rev. de Formas Consensuais de Solução De Conflitos | e-ISSN: 2525-9679 | Goiânia| v. 5 | n. 1 | p. 1-20| Jan/Jun. 2019 
para resolver sua questão. Assim, entende-se que a mediação sanitária é uma alternativa viável e satisfatória para se evitar a judicialização e para aumentar o acesso à Justiça do cidadão. Ademais, pode-se, inclusive, entender que com a mediação sanitária sendo uma opção para resolução dos conflitos, a judicialização pode voltar ao seu patamar de legítima e democrática, pois já não seria excessiva e nem prejudicial, uma vez que provavelmente só os casos que não fossem resolvidos através de métodos extrajudiciais de solução de conflitos é que seriam demandados no Judiciário.

\section{REFERÊNCIAS}

ASSIS, Gilmar de. A ação institucional de mediação sanitária: direito, saúde e cidadania. Cadernos Ibero-Americanos de Direito Sanitário, Brasília, v.2, n.2, p. 460-471, jul./dez., 2013. Anais dos III Congresso Iberoamericano de Direito Sanitário / II Congresso Brasileiro de Direito Sanitário. Disponível em: < https://www.cadernos.prodisa.fiocruz.br/index.php/cadernos/article/view/98/140> Acesso em 20 nov. 2018.

ASSIS, Gilmar de. Mediação sanitária: direito, saúde e cidadania. Conselho Nacional de Secretários de Saúde - CONASS - para entender a gestão do sus, $1^{\circ}$ edição, 2015. Disponível em: < http://www.conass.org.br/biblioteca/pdf/colecao2015/CONASS-DIREITO_A_SAUDEART_14B.pdf >. Acesso em 22 nov. 2018

BACELLAR, Roberto Portugal. Mediação e arbitragem. 2. ed. São Paulo: Saraiva, 2016.

BARROSO, Luís Roberto. Judicialização, ativismo judicial e legitimidade democrática. Anuario iberoamericano de justicia constitucional, n. 13, p. 17-32, 2009.

BRASIL. LEI N. 13.140, de 26 de junho de 2015. Dispõe sobre a Mediação entre particulares como meio de solução de controvérsias e sobre a autocomposiçao de conflitos no âmbito da administração pública. Disponivel em:

<http://www.planalto.gov.br/ccivil_03/_Ato2015-2018/2015/Lei/L13140.htm>. Acesso em 20 nov. 2018.

CARDOSO, Henrique Ribeiro. O paradoxo da judicialização das políticas públicas de saúde no Brasil: um ponto cego do direito?. Rio de Janeiro: Lumen Juris, 2016.

CRUZ, Marco Tulio Thomé da; NEZ, Brunna Agostini de. A contribuição da mediação sanitária para a desjudicialização do direito à saúde. Seminário Internacional de Direitos Humanos e Democracia, [S.1.], dez. 2017. Disponível em: $<$ https://www.publicacoeseventos.unijui.edu.br/index.php/direitoshumanosedemocracia/articl e/view/8658>. Acesso em 20 nov. 2018.

Rev. de Formas Consensuais de Solução De Conflitos | e-ISSN: 2525-9679 | Goiânia| v. 5 | n. 1 | p. 1-20| Jan/Jun. 2019 
DELDUQUE, Maria Célia. A Mediação Sanitária como novo paradigma alternativo à judicialização das políticas de saúde no Brasil. Conselho Nacional de Secretários de Saúde - CONASS - para entender a gestão do sus, $1^{\text {a }}$ edição, 2015, Disponível em $<$ http://www.conass.org.br/biblioteca/pdf/colecao2015/CONASSDIREITO_A_SAUDEART_9B.pdf >. Acesso em 22 nov. 2018.

DELDUQUE, Maria Célia; CASTRO, Eduardo Vazquez de. A mediação como alternativa viável à judicialização das políticas de saúde no Brasil. Saúde em Debate, v. 39, n. 105, p 506-513, abr./jun., 2015. Disponível em <http://www.scielo.br/pdf/sdeb/v39n105/0103-1104sdeb-39-105-00506.pdf> Acesso em 15 nov. 2018

MACHADO, Felipe Ranguel de Souza. Contribuições ao debate da judicialização da saúde no Brasil. Revista De Direito Sanitário, v.9, n. 2, 73-91, jul./out. 2008. Disponível em < https://www.revistas.usp.br/rdisan/article/view/13118/14921> Acesso em 15 nov. 2018.

MARQUES, Silvia Badim. Judicialização do direito à saúde. Revista de Direito Sanitário, v. 9, n. 2, p. 65-72, jul./out. 2008.

MORAIS, José Luis Bolzan de; SPENGLER, Fabiana Marion. Mediação e arbitragem: alternativa à jurisdição. 2. ed. rev. e ampl. Porto Alegre: Livraria do Advogado Editora, 2008.

NASCIMENTO, Dulce. Mediação de Conflitos na Área da Saúde: experiência portuguesa e brasileira. Cadernos Ibero-americanos de Direito Sanitário, v. 5, n. 3, p. 201-211, 2016.

OLIVEIRA, Maria dos Remédios Mendes. A judicialização da saúde no Brasil. Tempus Actas de Saúde Coletiva, v. 7, n. 1, p. 79-90, 2013.

RIBEIRO, Wesllay Carlos. A mediação como meio de resolução de conflitos na área de saúde. Revista de Direito Sanitário, v. 18, n. 3, p. 62-76, 2018.

SOUZA, Luciane Moessa de. Mediação, acesso à justiça e desenvolvimento institucional. In: SOUZA, Luciane Moessa de (Coor.). Mediação de conflitos: novo paradigma de acesso à justiça. Santa Cruz do Sul: Essere nel Mondo, 2015.

VENTURA, Miriam et al. Judicialização da saúde, acesso à justiça e a efetividade do direito à saúde. Physis: Revista de Saúde Coletiva, v. 20, p. 77-100, 2010. Disponível em < https://www.scielosp.org/pdf/physis/2010.v20n1/77-100/pt> Acesso em 15 nov. 2018. 